\title{
Correction to: Sensation weighting in duration discrimination: A univariate, multivariate, and varied-design study of presentation-order effects
}

\author{
Åke Hellström ${ }^{1}$ - Geoffrey R. Patching ${ }^{2}$ - Thomas H. Rammsayer ${ }^{3}$ \\ Published online: 26 May 2020 \\ (C) The Psychonomic Society, Inc. 2020
}

Correction to: Attention, Perception, \& Psychophysics https://doi.org/10.3758/s13414-020-01999-z

Due to a printing error, the factor "2" was missing in the last line of Equation 9. It has now been reinstated. The original article has been corrected.

The online version of the original article can be found at https://doi.org/ 10.3758/s13414-020-01999-Z

Åke Hellström
hellst@psychology.su.se

1 Department of Psychology, Stockholm University, SE-10691 Stockholm, Sweden

2 Lund University, Lund, Sweden

3 University of Bern, Bern, Switzerland 